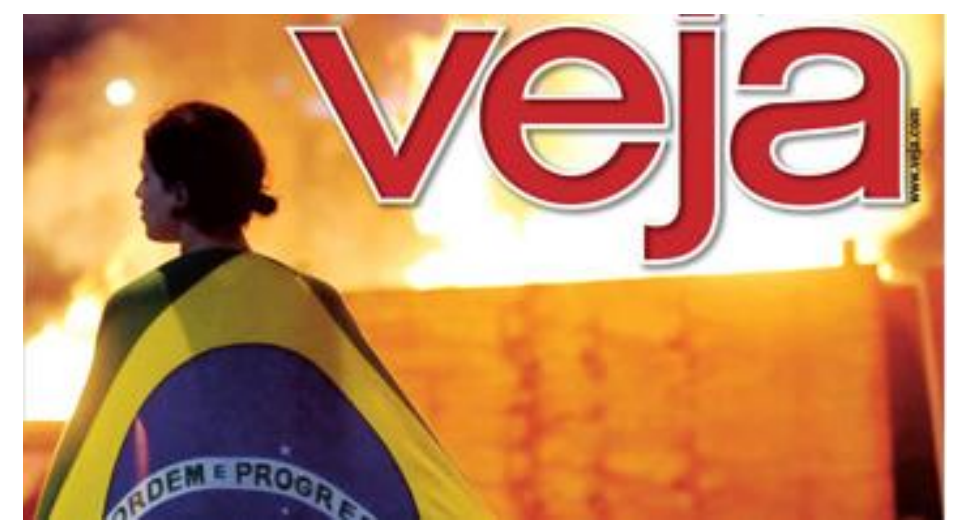

\title{
Uma análise discursiva da veiculação das manifestações de junho de 2013 pela revista Veja
}

\section{A discursive analysis of the Brazilian media on the June 2013 popular demonstrations}

\section{Resumo}

\section{Raquel Noronha ${ }^{1}$}

As manifestações de junho de 2013, contra o aumento da tarifa do transporte público, mobilizaram a mídia em geral, que procurou explicar o ocorrido.

Filiando-nos à Análise de Discurso de perspectiva materialista, analisamos duas edições da revista Veja observando que, apesar de mudar o modo de enxergar as manifestações, o efeito de neutralidade permanece. A contribuição do presente texto é de fomentar a discussão sobre o efeito de neutralidade no discurso midiático.

Palavras-chaves: análise do discurso, grande mídia, manifestações

\section{Abstract}

We analyze discursively two editions of Veja magazine (19/06, 26/06) about the demonstrations against rising bus fares in June 2013, that took place in several cities in Brazil. We analyze how images of protesters and demonstrations are not the same in both editions. As well as the image that the media makes of itself: who can, not only presents the facts, as point directions.

Keywords: discours analyses, mainstream media, demonstrations

\footnotetext{
${ }^{1}$ Mestre em Linguística pelo IEL/UNICAMP. Instituto de Estudos da Linguagem/UNICAMP. Rua Sérgio Buarque de Holanda, no 571 CEP 13083-859 - Campinas - SP - Brasil. E-mail: raquelnoronha06@gmail.com
} 


\section{Introdução}

Neste trabalho, analisamos duas edições da Revista Veja (19 e 26 de Junho de 2013) sobre a repercussão das manifestações contra o aumento da tarifa do transporte público ocorridas neste mesmo mês em várias cidades do Brasil.

Escolhemos a revista Veja como lugar para trabalharmos nosso objeto de análise (a neutralidade no discurso midiático) porque a revista faz parte de um dos maiores conglomerados midiáticos do Brasil, o grupo Abril. O grupo detém uma parcela significativa de leitores e, portanto, têm uma influência significativamente relevante.

No período em que as manifestações ocorreram, a mídia em geral procurou entender e explicar o que estava acontecendo. Muito se falou que o 'povo acordou' e muita atenção foi dada ao fato de milhares de brasileiros irem às ruas se manifestar. Fato bastante comum em outros países, poderia apenas mostrar que, de uma maneira geral, não se tem o hábito de ver grandes manifestações de rua no Brasil. Mas acabou sendo motivo para uma parte da mídia apontar a necessidade (urgente) de uma mudança política.

Tomamos as duas edições da revista em questão porque nelas podemos observar uma substancial mudança de posição. Em um primeiro momento, é de represália a um "ato de badernagem". Enquanto na semana seguinte, é de reiterar a importância de se manifestar contra, não mais o motivo que os manifestantes empunhavam nos cartazes, mas a corrupção política do governo federal.

Vamos nos focar na seção "Carta ao Leitor” da revista, trazendo outras seções na medida em que contribuírem para nossa análise. Escolhemos nos focar nesta seção porque é onde, sistematicamente, a revista reafirma seu compromisso com a neutralidade e imparcialidade, objeto de nossas análises.

\section{A Análise do Discurso}

Filiamo-nos à Análise do Discurso $(\mathrm{AD})$ de perspectiva materialista. A AD permite compreender os sentidos e interpretá-los a partir de uma relação que se estabelece no discurso com sua exterioridade e a história. É na relação da linguagem com a história que o sentido se constitui.

A questão da materialidade é central à AD (a materialidade da história, da língua, do discurso), fazendo com que nem a história, nem a língua, nem o discurso sejam vistos/ tratados como um meio atravessável. Muito menos como um meio transparente de informação, que visaria como produto final das análises chegar à coisa, ao fato, à informação propriamente dita. 
A AD se constitui, de acordo com Pêcheux e Fuchs ([1975] 1997), numa articulação de três regiões, a Linguística - "como teoria dos mecanismos sintáticos e dos processos de enunciação ao mesmo tempo" (PÊCHEUX \& FUCHS, 1997, 163); o materialismo histórico - "como teoria das formações sociais e de suas transformações, compreendida aí a teoria das ideologias" (loc. cit.); e a "teoria do discurso, como teoria da determinação histórica dos processos semânticos" (op.Cit.,164). Estas regiões são atravessadas e articuladas por uma "teoria da subjetividade" proveniente da psicanálise.

A AD leva em conta a exterioridade do texto, ou seja as Condições Produção que lhe possibilitam produzir sentido. A análise ultrapassa o estudo puramente linguístico. $O$ discurso, objeto da $\mathrm{AD}$, é a um só tempo integralmente linguístico e integralmente histórico. Trata-se de um espaço teórico no qual se pode depreender a relação entre a língua, enquanto sistema de signos, e a ideologia, enquanto determinação histórica do sentido.

Os sentidos não estão já-lá; mas são construídos historicamente, e só significam porque já significaram antes. Os sujeitos não têm, portanto, “controle" sobre o que dizem e nem são origem do dizer; eles ocupam diferentes posições a partir das diferentes formações discursivas em que se inscrevem. O dizer não é neutro porque está inscrito em formações discursivas constituídas por famílias parafrásticas que determinam não só aquilo que pode/ deve ser dito, como também a maneira como se enuncia de uma determinada formação discursiva (FD). A inscrição do sujeito numa determinada FD, a um só tempo, interpreta o lugar social, e influi sobre este produzindo um imaginário acerca de uma inscrição adequada nestes lugares,

...esses lugares estão representados nos processos discursivos em que estão colocados em jogo. Entretanto, seria ingênuo supor que o lugar como feixe de traços objetivos funciona como tal no interior do processo discursivo; ele se encontra aí representado, isto é, presente, mas transformado; em outros termos, o que funciona nos processos discursivos é uma série de formações imaginárias que designam o lugar que A e B se atribuem cada um a si e ao outro, a imagem que eles se fazem de seu próprio lugar e do lugar do outro. (...) O que podemos dizer é apenas que todo processo discursivo supõe a existência dessas formações imaginárias. (PÊCHEUX, [1969], 1997)

O discurso não pode ser atravessado. A sua materialidade é analisada a partir de FDs (matrizes do sentido) e formações ideológicas, que dizem respeito à representação do sujeito ao se inscrever em um lugar social para falar. Não há neutralidade, porque o dizer sempre poderia ser outro. 
Os sujeitos não têm, portanto, "controle" sobre o que dizem e nem são origem do dizer; eles ocupam diferentes posições a partir das diferentes formações discursivas em que se inscrevem. Ou seja, o sujeito só enuncia através de sua inscrição em uma formação discursiva dada e é a partir dela que os sentidos vão ser "determinados" (como sendo uns e não outros).

A relação entre sujeito e linguagem é determinante para ambos: não é só a linguagem que determina aquilo que pode ou não ser dito (só se fala porque a língua já faz sentido); o sujeito, por meio de reformulações, produz deslocamentos nos sentidos já constituídos historicamente na/ pela linguagem. O sujeito não é inteiramente livre para dizer aquilo que quer (o dito como intencional), nem a língua é um sistema fechado que funciona como mero instrumento de comunicação: a linguagem é viva, porque existe na relação entre sujeitos, inscritos nos processos históricos, que estão continuamente promovendo deslocamentos no dizer.

\section{3. $O$ discurso midiático}

A mídia ocupa um espaço determinante na sociedade: exime-se de um caráter interpretativo, através de uma pretensa neutralidade, a partir da qual funciona como os olhos da sociedade moderna. É a mídia que tudo vê e tudo mostra, e é por ela que se pode saber (a verdade). Para Payer (2005), a mídia atua na sociedade contemporânea como um novo "texto fundamental". Contraposta à Igreja (e seus aparelhos) ou aos Estado (e seus aparelhos) - que têm, respectivamente, o templo e o tribunal como lugares privilegiados de circulação dos seus enunciados -, a mídia se caracteriza pela sua dispersão e onipresença.

Nesta seção, analisamos a imagem que o discurso midiático projeta da posição social que a revista em questão se inscreve para falar. Observemos o seguinte recorte:

1) Uma reportagem especial desta edição se dispõe a explicar o que querem os jovens brasileiros que estão vandalizando as ruas a pretexto de lutar contra o aumento de 20 centavos nas passagens urbanas. Eles querem protestar. (VEJA 19 de junho de 2013, seção Carta ao Leitor ) (grifos nossos).

A mídia fala de um lugar privilegiado no qual se poderia entender e explicar os fatos àqueles que, imaginariamente, não entendem, não sabem. Explicar os fatos seria, por efeito de sentido, constituído como trabalho da mídia; nesse recorte, no entanto, vaise além: não seria só seu trabalho, mas algo que estaria "disposta" a fazer. 
Observando os trechos "se dispõe a explicar o que querem" e "eles querem protestar", podemos dizer que o efeito de neutralidade que perpassa o discurso midiático faz coincindir, imaginariamente, a interpretação dos fatos com os fatos em si.

Para Mariani (1998, p.61) o discurso jornalístico é uma modalidade de discurso sobre

Os discursos sobre são discursos que atuam na institucionalização dos sentidos (...) De modo geral, representam lugares de autoridade em que se efetua algum tipo de transmissão de conhecimento

A este respeito, analisemos o seguinte recorte.

2) As manifestações de rua da semana passada mostraram de modo inequívoco que estão quebrados os canais de comunicação de imensa porção da sociedade brasileira com as instituições que deveriam representá-la. Não era novidade para ninguém que o distante planeta Planalto, Brasilha da Fantasia, vinha se tornando, governo após governo, uma entidade divorciada do Brasil real e focada apenas na arrecadação da maior carga fiscal entre os países emergentes. (VEJA 26 de junho de 2013, seção Carta ao Leitor) (grifos nossos)

O discurso midiático produz um efeito de apagar qualquer caráter interpretativo, projetando seu dizer como neutro. O discurso sobre os fatos coincidiria com os fatos em si, como podemos observar com o uso dos verbos ("mostraram", "deveriam”) o que é reforçado pela sequência discursiva "de modo inequívoco".

Fazendo crer que apresenta os fatos tais como são, com uma linguagem isenta de subjetividades, o discurso jornalístico atua à semelhança de um discurso pedagógico em sua forma mais autoritária. Se no discurso pedagógico autoritário cabe ao professor fazer a mediação entre o saber científico e os aprendizes de tal modo que (...) os alunos se veem diante de verdades incontornáveis (...), no discurso jornalístico mascara-se um apagamento da interpretação em nome de fatos que falam por si. (MARIANI,1998)

Não haveria interpretação no discurso midiático, tudo que haveria seriam fatos.

\section{O efeito de neutralidade no discurso midiático}

Nesta seção, vamos analisar a imagem das manifestações e dos manifestantes nas duas edições da revista Veja. A imagem que a mídia faz de si afeta seu discurso e por conseguinte o modo como vê os manifestantes e as manifestações. 


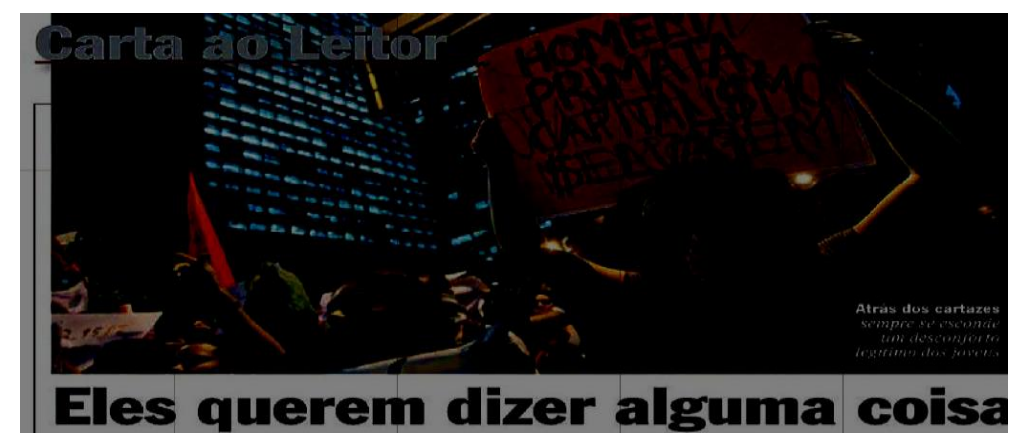

3) legenda da foto: "Atrás dos cartazes sempre se esconde um desconforto legítimo dos jovens" (VEJA 19 de junho de 2013, seção Carta ao Leitor) (grifos nossos)

Na Veja de 19 de junho, são "eles" os que falam ou tentam falar (“querem dizer"). Uma paráfrase possível para evidenciar a tentativa frustrada de tentar dizer algo sem êxito seria substituir "querem dizer" por "dizem":

3) Eles querem dizer alguma coisa.

3') Eles dizem alguma coisa

3") Eles dizem $X$.

Ao substituir "querem dizer" por "dizem", evidencia-se que em (3) ocorre uma tentativa frustrada: não se diz, tenta-se dizer. Alheio à vontade (de querer dizer) os manifestantes não conseguiriam dizer o que querem.

O que se é dito em (3'), no entanto, ainda é incerto (“alguma coisa”). Dessa maneira, em (3") podemos ver uma contraposição ao primeiro enunciado: se em (3) ocorre um tentativa em dizer algo; em (3"), algo, que é especificado, é dito.

Essa não-realização em (3) é evidenciada pela legenda da foto (“atrás dos cartazes sempre se esconde um desconforto legítimo dos jovens"). A tentativa frustrada de se dizer algo, "esconde" a real motivação: "um desconforto legítimo". Seria trabalho da mídia ler o por trás do (quase) dito e preencher-lhes suas lacunas da maneira certa.

Na edição da semana seguinte, a imagem dos manifestantes não é mais daqueles que não conseguem dizer o que querem. Observe: 


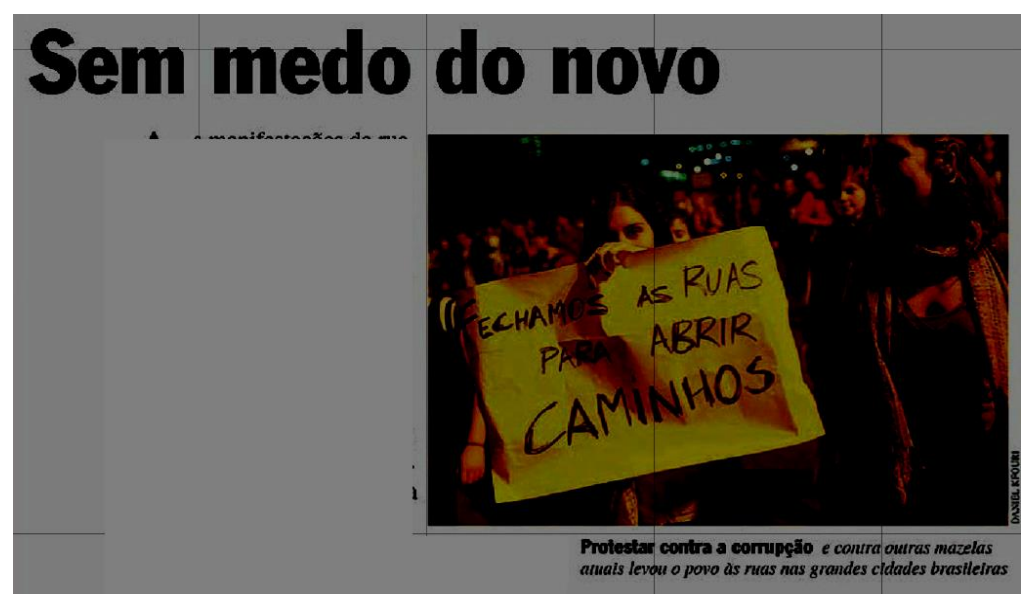

4) legenda da foto: "Protestar contra a corrupção e contra outras mazelas atuais levou o povo às ruas nas grandes cidades brasileiras” (VEJA 26 de junho de 2013, seção Carta ao Leitor) (grifos nossos)

$\mathrm{Na}$ veja de 26/06 é o povo (não mais os jovens) quem protesta e o discurso midiático poderia dizer contra o quê.

4') Protestar contra a corrupção e contra outras mazelas atuais levou o povo às ruas nas grandes cidades brasileiras

Podemos ver que a maneira de abordar as manifestações é distinta da que se vê desenhar pelo recorte que fizemos em 3.

3) Eles querem dizer alguma coisa

4) Sem medo do novo

No primeiro recorte há um esvaziamento dos protestos em si. Já no segundo, o discurso midiático aponta para um novo caminho político com o conclame do povo. É projetado um caráter de representação social às manifestações.

Na edição de 19/06, a imagem junto ao título da seção que lhe serve de legenda deslegitima, imaginariamente, as manifestações. Com a foto do jovem com máscara de macaco, é projetada uma imagem animalesca, primitiva dos manifestantes. O discurso midiático constrói uma imagem de que os manifestantes seriam incapazes de dizer e, talvez, saber, o que querem. Deslegitima-se, por efeito, a posição social dos manifestantes: seriam jovens vândalos que só querem protestar. É relacionada à imagem de "jovens" a pouca idade com a falta de sabedoria, reforçada pelo uso da força. Como no recorte a seguir:

5) Há uma grande chance de que boa parte da rapaziada que, na semana passada, foi às ruas esteja apenas dando vazão às pressões hormonais pelo exercício passageiro do socialismo revolucionário. Afinal, como disse o inglês Winston Churchill, "se você não é um liberal aos 20 anos não tem coração, e se não se torna um conservador aos 40 você não tem cérebro (VEJA 19 de junho de 2013, reportagem especial) 
Podemos observar o discurso midiático, por efeito, construindo uma imagem dos manifestantes que explica as manifestações. Os "jovens" protestam porque faz parte de uma escala natural de evolução: aos 20 anos, liberal porque fisiologicamente imaturo; aos 40, a maturidade é atrelada à capacidade intelectual e política. A mídia trabalha produzindo um efeito de exterioridade que lhe autoriza a não só interpretar a atitude dos jovens como também a traduzi-la.

6) Eles têm em comum [com "jovens americanos" do "Ocupe Wall Street", com "estudantes ingleses" "em protesto contra cobrança de algumas taxas nas universidades"] principalmente o fato de pertencer às classes médias e ricas de seus respectivos países. (...) Os repórteres de VEJA entrevistaram dezenas de jovens nas ruas de São Paulo e do Rio de Janeiro que, candidamente, confessaram nunca andar de ônibus, mas protestavam mesmo assim em nome de suas empregadas domésticas. Fosse esse mesmo o caso, seria mais eficiente pedir aos pais um aumento de salário para elas. (VEJA 19 de junho de 2013, seção Carta ao Leitor) (grifos nossos)

7) Os brasileiros que estão indo às ruas não admitem mais ser usados como massa de manobra por partidos e políticos profissionais. (...) neste momento, o imperativo é ouvir as ruas e esperar que essa energia pura seja canalizada para a construção de instituições mais representativas dos anseios populares legítimos. O erro fatal agora é fechar os ouvidos. É temer o novo. (VEJA 26 de junho de 2013, seção Carta ao Leitor) (grifos nossos)

Colocando os recortes acima lado a lado, podemos perceber um deslocamento da configuração dos protagonistas dos protestos: no recorte (6), os manifestantes pertencem às classes média e rica; no recorte (7), os manifestantes são "os brasileiros" indignados contra o governo.

Na edição do dia 19 de junho, a imagem projetada dos manifestantes é a de quem não saberia o que diz e nem o que quer (3), nem teria um motivo real para protestar (“candidamente, confessaram nunca andar de ônibus, mas protestavam mesmo assim", 6). O discurso midiático desautoriza o lugar do qual os manifestantes falam, trazendo como efeito de sentido uma oposição entre ricos/ pobres que diz respeito a quem pode reivindicar o transporte público. A responsabilidade pelo "motivo" das manifestações é deslocada do público (o Estado) para o privado (os pais). Nesse sentido a revista oferece como alternativa às manifestações protagonizadas por jovens que não usariam transporte público: que eles peçam a seus pais um aumento de salário às empregadas. Isso reforça $\mathrm{o}$ esvaziamento das manifestações que vimos no recorte (1 - “Eles querem protestar Ø”).

Já na Veja de 26/06, a imagem produzida da manifestação adquire viés político e a figura dos manifestantes é retomada por "os brasileiros" (7), "o povo" (4), "porção da sociedade brasileira" (2). O que produz um efeito de sinonímia entre manifestantes, os 
brasileiros, o povo. É construída uma imagem abrangente dos manifestantes, o que não significa que estão todos aí incluídos, como podemos observar no recorte 2 ("porção da sociedade brasileira”). A mídia mesma não se inclui na imagem de manifestantes que projeta em seu discurso: apesar de autorizá-la, permanece de fora, o que a possibilitaria intervir nos fatos.

De acordo com Mariani (1998), o discurso jornalístico “contribui na constituição do imaginário social e na cristalização da memória do passado, bem como na construção da memória do futuro". A este respeito, observemos o seguinte recorte.

8) Na sexta-feira, o Movimento Passe Livre (MPL), que iniciou os protestos em São Paulo, anunciou sua retirada de cena. Oficialmente, declarou que tomou a decisão por já ter atingido seu objetivo. A verdade, porém, é que, seguindo a lei histórica segundo a qual as revoluções raramente são concluídas pelos que as iniciam, o MPL tornou-se irrelevante ao cabo de alguns poucos dias. Os caminhos que as manifestações tomarão, é claro, está no campo da especulação. A história mostra que os grandes espasmos populares espontâneos nem sempre prenunciam mudanças políticas de mesma coloração e envergadura. $O$ famoso Maio de 68 na França culminou com a eleição de um presidente conservador, Georges Pompidou. No mesmo fim de década, o movimento pacifista "flower power" conquistou corações e mentes de milhões, mas quem se elegeu presidente foi mesmo o direitista Richard Nixon. O certo, porém, é que as ruas das grandes cidades brasileiras parecem agora vacinadas contra o proselitismo, as ideologias velhas e o populismo. Essa é a verdadeira revolução. (VEJA 26 de junho de 2013, reportagem principal) (grifos nossos)

Ao apresentar a "lei histórica" e como ela funciona, o discurso midiático constrói imaginariamente $a$ verdade. Ao falar em lei é produzido por efeito uma regra. Imutável ao atrelar à lei a história: vai ser assim porque já foi assim, com "raras" exceções.

A imagem que a mídia faz da posição que ocupa é daquela responsável por “canalizar a energia pura" apontando um rumo. É produzido o lugar privilegiado que a mídia ocupa para falar - daquela que não só mostraria a verdade, como também de quem apontaria caminhos possíveis e mais prováveis (desejáveis?).

A verdadeira indignação não seria contra o aumento, mesmo tendo sido este o estopim das manifestações. Produzindo um efeito de verdade incontestável ao trazer "a lei histórica", o discurso midiático exclui aqueles que primeiro se manifestaram para apontar novos protagonistas (“A história mostra que os grandes espasmos populares espontâneos nem sempre prenunciam mudanças políticas de mesma coloração e envergadura"). 
9) Na quarta-feira passada, Lula - depois de ouvir mais queixas de sindicalistas orientou-os a aderir às manifestações. No dia anterior, o ex-presidente se reuniria justamente com Dilma e o prefeito de São Paulo, Fernando Haddad, para tratar do assunto. Ao protagonizar esse encontro, Lula reforçou a imagem de que é o mentor da presidente e, de quebra, jogou Haddad aos leões. O ex-presidente espalhou a versão de que Haddad foi o principal culpado pelo acirramento da situação em São Paulo ao menosprezar os manifestantes. A ordem de Lula foi para que o prefeito reduzisse as tarifas, ignorando os argumentos de que não havia dinheiro para isso e que a revogação dos aumentos abriria um precedente perigoso, que poderia inviablizar seu governo. Nada disso importava a Lula. Para ele, a meta é estancar o desgaste do PT. Afinal. 2014 está aí - com Dilma ou com ele. (VEJA 26 de junho de 2013, reportagem principal) (grifos nossos)

Aqui, o ex-presidente Lula aparece como líder do governo: é ele quem marca reuniões, orienta estratégias, manda reduzir as tarifas. Mas esta certa posição de líder produzida pelo discurso midiático não é positiva, uma vez que o ex-presidente é retratado como aquele que não sabe o que está fazendo ("ignorando os argumentos de que não havia dinheiro para isso e que a revogação dos aumentos abriria um precedente perigoso, que poderia inviabilizar seu governo"), que cria inverdades ("espalhou a versão") e que só estaria interessado nas eleições de 2014 (“Afinal. 2014 está aí - com Dilma ou com ele”).

10) O choque realmente pertubador pegou em cheio os partidos de esquerda, e em especial o PT, que se consideravam donos das ruas. Não são. As ruas brasileiras hoje pertencem aos brasileiros que não se sentem representados por essas legendas e que fizeram questão de obrigar os militantes do PT, do PSOL e de outras agremiações a baixar suas bandeiras quando tentaram participar dos protestos. Na quinta-feira passada, sindicalistas da CUT foram vigorosamente afastados de uma passeata no Rio de Janeiro, quando, obedecendo a ordens do ex-presidente Lula, quiseram se passar por manifestantes. Na Avenida Paulista, o coração de São Paulo, a mesma rejeição foi dirigida a petistas tarefeiros que, obedientes ao chamamento da direção nacional, imaginaram poder se misturar aos demais, fingindo comungar da indignação geral com a corrupção, a impunidade e os gastos públicos de péssima qualidade. Foram violentamente lembrados de que estão no poder. São, portanto, alvo da indignação. (VEJA 26 de junho de 2013, seção Carta ao Leitor) (grifos nossos)

Ao dizer "se passar por", "poder se misturar" diferencia-se imaginariamente os manifestantes dos sindicalistas da CUT e dos petistas, seriam posições não-coincidentes. O discurso midiático imaginariamente projeta o governo petista como o alvo da indignação deslocando o objeto das manifestações que, como vimos no recorte (9), seria irresponsabilidade continuar a residir na revogação do aumento das passagens de ônibus. E o ex-presidente Lula é projetado ocupando uma certa posição de líder que, como vimos, é o "mentor da presidente" (9), que tem a seu serviço os sindicalistas ("orientou os sindicalistas a aderir às manifestações" - 9) e os filiados ao mesmo partido político que o seu ("petistas tarefeiros que, obedientes ao chamamento da direção nacional" - 10). É ele quem comandaria aqueles que, como ele, comungariam do proselitismo, das ideologias velhas e do populismo (8) a se passarem por manifestantes (brasileiros). 
O discurso midiático desloca o objetivo das manifestações para um objetivo melhor, mais adequado, de outra "cor" e "envergadura" (8). O objetivo inicial seria uma “energia pura", que não teria potencial senão através de "espasmos populares”. Ou seja, seriam matéria-prima, bruta, que precisaria ainda ser "canalizada". O desfecho seria a retirada de governantes incapazes e populistas do governo, mais especificamente da presidência.

Em outro espaço da revista, na seção Livros (edição de 26/06), é resenhado o novo livro do ex-presidente Fernando Henrique Cardoso, Pensadores que inventaram o Brasil. Ao mesmo tempo em que, ao longo da matéria principal, é construída uma imagem de líder negativa, nesta seção, podemos ver a construção da imagem de um líder culto. Como podemos observar no título da reportagem que é Pensador e pensadores, fazendo um jogo de palavras que brinca com o título do livro: os pensadores seriam objeto do livro, e o pensadorØ, seria o autor.

11) Em uma coletânea de ensaios, Fernando Henrique Cardoso revisa os intelectuais que o formaram (VEJA 26 de junho de 2013, seção Livros - subtítulo) (grifo nosso)

12) Político habilidoso na formação de alianças que possibilitaram a grande arrancada modernizante do país, Fernando Henrique Cardoso nunca abandonou por completo o pensamento acadêmico. Foi, à sua maneira, um presidente-sociólogo. (...) Através do exame desses grandes pensadores do Brasil, tem-se um vislumbre do presidente-sociólogo. (VEJA 26 de junho de 2013, seção Livros) (grifo nosso)

Trazemos estes recortes para ilustrar como a construção da exterioridade se dá na materialidade do discurso a partir das formações discursivas (Pêcheux [1975] 1997) em que o discurso midiático se inscreve.

Ao nomear o ex-presidente Fernando Henrique Cardoso de "presidentesociólogo", vincula-se o cargo que ocupou à sua formação acadêmica. E a comparação, apesar de não estar explícita, é constituída ao se trazer na mesma edição exemplo de líderes inadequados e de um "político habilidoso" e culto. Mas o político habilidoso não aparece senão através de um "vislumbre".

\section{Conclusão}

A mídia trabalha produzindo um efeito de exterioridade que lhe autorizaria a, não só interpretar, como também traduzir os fatos. O trabalho de desautorizar discursos funcionaria ao preencher-lhes suas lacunas da maneira certa que, pelo apagamento do caráter interpretativo, é construída como única possível. 
A imagem que a mídia faz da posição que ocupa é a daquela responsável por “canalizar a energia pura" apontando um rumo. É produzido o lugar privilegiado que a mídia ocupa para falar - daquela que não só mostra a verdade, como também de quem aponta caminhos possíveis.

O efeito de neutralidade recorrentemente aparece no discurso midiático. É através dele que a mediação dos fatos adquiriria um caráter incontestável. A neutralidade, a partir da qual a mídia imagina falar, traveste o viés político, a tomada de posição. Conferindo àquilo que diz o status de transmissão fiel dos fatos, de tradução exata de falas e ações e, por isso, a verdade pura e incontestável.

\section{Referências bibliográficas}

MARIANI, Bethania. O PCB e a imprensa. Os comunistas no imaginário dos jornais 1922-1989. Rio de Janeiro: Revan; Campinas: Editora da UNICAMP, 1998.

ORLANDI, Eni Puccinelli. Análise do Discurso: principios e procedimentos. Campinas, SP: Pontes, 4a ed, 2002.

PAYER, Maria Onice. Linguagem e sociedade contemporânea. Sujeito, Mídia, Mercado. Campinas, SP: Revista Rua. n.11, mar, 2005.

PÊCHEUX, Michel. Análise Automática do Discurso. Em GADET, F.; HAK, T. Por uma análise automática do discurso: uma introdução à obra de Michel Pêcheux. 3a ed., Campinas, SP: Editora da UNICAMP, [1969] 1997.

. A propósito de uma análise automática do discurso: atualização e perspectivas. Em GADET, F.; HAK, T. Por uma análise automática do discurso: uma introdução à obra de Michel Pêcheux. 3a ed., Campinas, SP: Editora da UNICAMP, [1975] 1997.

. Semântica e Discurso - uma crítica a afirmação do óbvio. Campinas, SP:

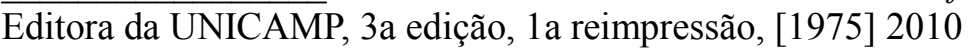


Para citar essa obra:

NORONHA, R.. Uma análise discursiva da veiculação das manifestações de junho de 2013 pela revista Veja. In: $R U A$ [online]. no. 21. Volume 1, p. 143 - 154 - ISSN 1413-2109. Junho/2015. Consultada no Portal Labeurb - Revista do Laboratório de Estudos Urbanos do Núcleo de Desenvolvimento da Criatividade.

http://www.labeurb.unicamp.br/rua/

Capa: Revista Veja, 26 junho de 2013

Laboratório de Estudos Urbanos - LABEURB

Núcleo de Desenvolvimento da Criatividade - NUDECRI

Universidade Estadual de Campinas - UNICAMP

http://www.labeurb.unicamp.br/

Endereço:

LABEURB - LABORATÓRIO DE ESTUDOS URBANOS

UNICAMP/COCEN / NUDECRI

CAIXA POSTAL 6166

Campinas/SP - Brasil

CEP 13083-892

Fone/ Fax: (19) 3521-7900

Contato: http://www.labeurb.unicamp.br/contato 